\title{
Associations of prepartum plasma cortisol, haptoglobin, fecal cortisol metabolites, and nonesterified fatty acids with postpartum health status in Holstein dairy cows
}

\author{
J. M. Huzzey, ${ }^{*}$ D. V. Nydam,† R. J. Grant,‡ and T. R. Overton*1 \\ *Department of Animal Science, Cornell University, Ithaca, NY 14853 \\ †Department of Population Medicine and Diagnostic Sciences, College of Veterinary Medicine, Cornell University, Ithaca, NY 14853 \\ ¥William H. Miner Agricultural Research Institute, Chazy, NY 12921
}

\begin{abstract}
The association between negative energy balance and health has led to the testing of blood analytes such as nonesterified fatty acids (NEFA) to identify opportunities for improving the management of transition dairy cows. The objective of this study was to evaluate whether prepartum analytes associated with stress (cortisol) or inflammation (haptoglobin) could also identify dairy cattle at increased risk for health complications after calving. Prepartum blood and fecal samples were collected once weekly from 412 Holstein dairy cows on 2 commercial dairy farms (at wk $-3,-2$, and -1 relative to calving) and analyzed for concentrations of NEFA, haptoglobin (Hp), and cortisol in plasma and cortisol metabolites in feces. Retained placenta (RP), displaced abomasum (DA), subclinical ketosis (SCK), high Hp concentration (HiHp), and death were recorded up to $30 \mathrm{~d}$ in milk (DIM), and animals were subsequently categorized into 3 health categories: (1) no disorder of interest (NDI); (2) one disorder (RP, DA, SCK, or HiHp); or (3) more than one disorder (RP, DA, SCK, HiHp) or death. With the exception of prepartum NEFA, no associations were detected between prepartum concentrations of our analytes of interest and the occurrence of one disorder (RP, DA, SCK, or HiHP) by 30 DIM. Haptoglobin concentration tended to be greater during wk -2 and -1 in cows that developed more than one disorder or that died by 30 DIM; however, when calving assistance was included as a covariate in the analysis prepartum, Hp was no longer a significant risk factor for this postpartum health outcome. Primiparous cows with plasma cortisol concentrations $>22.2$ $\mathrm{nmol} / \mathrm{L}$ during wk -2 had reduced odds [odds ratio (OR) $0.41 ; 95 \%$ confidence interval (CI) 0.17-0.98] of developing more than one disorder or death by 30 DIM, whereas multiparous cows with plasma cortisol $>34.1$
\end{abstract}

Received April 29, 2010.

Accepted August 19, 2011.

${ }^{1}$ Corresponding author: tro2@cornell.edu
nmol/L during wk -2 tended to have greater odds (OR $2.53 ; 95 \%$ CI $0.87-7.37$ ) of developing more than one disorder or death by 30 DIM. Individual variation in daily cortisol secretion patterns and stress responses to the restraint and handling associated with sample collection make prepartum plasma cortisol data and its relationship to postpartum health difficult to interpret. Among multiparous cows, for every 500-unit (ng/g of fecal dry matter) increase in fecal cortisol metabolite concentration during wk -2 , cows had increased odds (OR 1.41; 95\% CI 1.12-1.79) of developing more than one disorder or dying after calving. For multiparous cows, every $0.15 \mathrm{mmol} / \mathrm{L}$ increase in plasma NEFA concentration during any of the 3 wk before calving was associated with an approximately 2 -fold increase in the odds of developing more than one disorder or dying by 30 DIM. Fecal cortisol metabolite concentration during the prepartum period did not predict which cows would go on to develop more than one disorder or die within 30 DIM as accurately as prepartum NEFA concentration; therefore, this analyte is not a suitable substitute for NEFA for assessing opportunities to improve herd health.

Key words: transition period, cortisol, haptoglobin, health

\section{INTRODUCTION}

Maintaining healthy dairy cows during the periparturient period continues to be a challenge. Several researchers (Kaneene et al., 1997; Oetzel, 2004; LeBlanc et al., 2005; Ospina et al., 2010a) have explored testing of blood analytes to identify opportunities for improved dairy cow management. This work has focused primarily on the relationship between health and analytes related to energy status (e.g., NEFA and BHBA). For example, Ospina et al. (2010a) reported that cows with circulating NEFA concentrations $>0.29 \mathrm{mEq} / \mathrm{L}$ during the 2 -wk period before calving had twice the risk for postpartum disorders (displaced abomasum, clinical ketosis, metritis, or retained placenta). Furthermore, 
cows with circulating NEFA concentrations $>0.57$ $\mathrm{mEq} / \mathrm{L}$ during the 2 -wk period after calving had 4 times the risk for these disorders compared with cows with NEFA concentrations below this cutpoint (Ospina et al., 2010a).

Although evidence continues to mount in support of NEFA and BHBA as useful analytes for predicting disease, few studies have explored whether alternative physiological analytes may also be useful predictors of postpartum health status. During the transition period, environmental and management changes occur within a relatively short period, including social regroupings, mixing of heifers and cows, and changes in diet formulation (Grant and Albright, 1995). These situations represent potential stressors that may affect health and performance if individual coping strategies cannot effectively adapt to these challenges. Physiological indicators of stress, particularly during the period before calving, may reveal opportunities for improvements in transition cow management.

Changes in the activity and functioning of the hypothalamic-pituitary-adrenal (HPA) axis are often used to quantify an animal's response to a potential stressor (Mormède et al., 2007). Increased plasma cortisol concentrations have been associated with management and environmental factors thought to be stressful. Circulating cortisol concentrations in cattle increase in response to overstocking (Friend et al., 1979), transportation (Lay et al., 1996), and repenning or regrouping (Friend et al., 1977; Gupta et al., 2005). Evidence also shows that changes in adrenal activity precede health disorders. Peter and Bosu (1987) reported that cows that went on to develop retained placenta $(\mathbf{R P})$ after calving had higher serum cortisol concentrations $6 \mathrm{~d}$ before parturition compared with cows without RP. Despite these relationships, plasma cortisol is likely a poor analyte for field diagnostics for several reasons. Restraint and handling, which are required during blood sampling, can activate the HPA axis and raise circulating cortisol concentrations quickly (Cook et al., 2000). Further, the release of cortisol from the adrenal gland throughout the day is pulsatile, has a diurnal cycle, and is subject to substantial individual variation (Thun et al., 1981). Thus, to obtain an accurate assessment of HPA axis activity for the day, as was done in the study of Peter and Bosu (1987), multiple plasma cortisol samples would have to be evaluated.

A practical analyte for field diagnostics or for the identification of herds or individuals at increased risk for disease is one that does not require repeated sampling over the course of a day or days. Fecal cortisol metabolites may be an alternative to plasma cortisol as a measure of the stress response in cattle, due to the feedback-free nature of the sampling method (Palme et al., 1999). The correlation between fecal cortisol metabolites (11,17-dioxoandrostanes) and plasma cortisol has been validated in ruminants by $\mathrm{ACTH}$ and dexamethasone tests (Palme et al., 1999); it was determined that concentration of fecal cortisol metabolites paralleled that of cortisol in the blood with a delay time of 10 to $12 \mathrm{~h}$. Changes in DMI, which are common during the transition period, can alter manure output (Nennich et al., 2005); however, previous research suggests that level of intake does not meaningfully influence the concentration of steroid metabolites in the feces (Rabiee et al., 2001). Further, increased fecal cortisol metabolite concentrations in cattle have been reported in response to transport stress (Palme et al., 2000), suggesting that this measure has potential for describing natural fluctuations in cortisol secretion arising from environmental stressors.

Environmental stressors also induce an acute phase response in cattle. Transportation and regrouping in cattle increase acute phase proteins such as haptoglobin (Hp) and serum amyloid A (Arthington et al., 2003; Lomborg et al., 2008). The acute phase response is activated during periods of inflammation, tissue damage, and infection. Although many acute phase proteins exist, $\mathrm{Hp}$ has been of particular interest for the detection of sick animals because of its high relative increase during the acute phase response from the low concentration threshold observed during normal or healthy conditions (Eckersall, 2000). Several researchers have demonstrated that Hp can be used as a diagnostic analyte (Skinner et al., 1991; Hirvonen et al., 1999; Sheldon et al., 2001). Huzzey et al. (2009) reported an increase in Hp 3 d before the onset of clinical signs of metritis; however, more research is needed to determine whether $\mathrm{Hp}$ can predict cows at risk for disease when measured during the weeks leading up to calving. Greater prepartum Hp concentrations among cows that develop health complications after calving could indicate subclinical infections not yet detectable through visual symptoms, increased susceptibility to stressful environmental conditions, or even severe disruptions in energy balance. Changes in energy status and lipid metabolism during the transition period can lead to excessive NEFA infiltration of the liver and fatty liver syndrome. Similar to infection or trauma, fatty infiltration represents a harmful stimulus to liver parenchymal cells, and consequently these cells will increase the production of Hp (Katoh, 2002).

The objective of this study was to evaluate the association between prepartum concentrations of plasma cortisol, fecal cortisol metabolites, and plasma Hp with postpartum health status. The association between prepartum NEFA and postpartum health status was also evaluated so that our analytes of interest could be 
discussed relative to a well-described metabolic predictor of disease.

\section{MATERIALS AND METHODS}

\section{Animals, Housing, and Diet}

The Cornell University Institutional Animal Care and Use Committee approved all procedures involving animals before the beginning of the study. This study was conducted between February 2008 and July 2008 on 2 commercial Holstein dairy herds in New York State. Herd size of the 2 farms ranged from approximately 1,300 to 1,500 milking cows. During this time, a convenience sample of 12 to 20 animals that were within 4 wk of calving was selected each week for enrollment. Any animals that were visibly sick or lame were not enrolled in the study. On farm A, 202 cows were sampled [113 multiparous cows (MP) and 89 primiparous cows $(\mathbf{P P})]$ and on farm B 210 cows were sampled (117 MP and $93 \mathrm{PP}$ ) for a total enrollment of 412 animals in the study. Primiparous cows were purposely targeted to increase the number of PP cows sampled to ensure that statistically valid comparisons between parities could be made. The average parity (mean $\pm \mathrm{SD}$ ) of all animals (including the calving event that occurred during the course of the study) was 2.3 \pm 1.6 on farm $\mathrm{A}$ and $2.1 \pm 1.4$ on farm $\mathrm{B}$, with an overall average of $2.2 \pm 1.5$. Housing facilities on each farm included freestalls for the close-up and fresh cow pens, and separate maternity pens consisting of strawbedded packs. Cows were moved to the maternity pen when they showed physical signs of imminent calving (e.g., placenta or feet visible). After calving, cows were moved at the discretion of the farm staff into either a high-lactation fresh group or a transition fresh group if complications associated with calving occurred (i.e., clinical disease). On farm B, PP and MP cows were housed separately after calving; in all other periods, cows of all parities were commingled.
Cows in both herds were fed once daily in the morning, with feed push-ups occurring at regular intervals throughout the day. Weekly samples of the TMR were collected from the close-up and fresh cow groups. The weekly TMR samples for each farm were combined into 4-wk composite samples and submitted to a commercial laboratory for wet chemistry analysis (Dairy One Cooperative Inc., Ithaca, NY). The results of this analysis are provided in Table 1 . Cows had ad libitum access to water and fresh cows were milked 3 times daily. Body condition score (Wildman et al., 1982) for each individual was recorded weekly beginning $4 \mathrm{wk}$ before the expected calving date and once within the week following calving. Farm staff were responsible for collecting calving information, including calving ease (assisted versus nonassisted), twinning, and calves born dead on arrival (DOA). Calving data and pre- and postpartum BCS were used as covariates in the statistical analysis.

\section{Blood and Fecal Sample Collection and Analysis}

Blood and fecal samples were collected weekly from the 412 enrolled cows beginning approximately $4 \mathrm{wk}$ before each individual's expected calving date and continued until parturition. For all experimental cows a postpartum blood sample was collected between 3 and 10 DIM. Blood was collected from the coccygeal vessel into 10-mL sterile tubes coated with sodium heparin (BD Vacutainer, Franklin Lakes, NJ) and then stored in coolers until they could be returned to the laboratory for processing. Plasma was harvested after centrifugation $\left(2,800 \times g\right.$ for $15 \mathrm{~min}$ at $\left.4^{\circ} \mathrm{C}\right)$, and stored at $-20^{\circ} \mathrm{C}$ for later analyses. Plasma concentrations of NEFA and Hp were measured by enzymatic analysis (NEFA-C, Wako Pure Chemical Industries, Osaka, Japan; Phase Range Haptoglobin Assay, kit no. TP801, Tridelta Diagnostics Ltd., Morris Plains, NJ). Intra- and interassay CV for the NEFA assay were 2.2 and $4.7 \%$, respectively, and for the Hp assay were 6.2 and $10.0 \%$, respectively. All spectrophotometric measurements were conducted us-

Table 1. Component analysis (mean \pm SD; \% of DM unless otherwise noted) of 4-wk composite TMR samples collected between February and July 2008 from farms A and B

\begin{tabular}{|c|c|c|c|c|}
\hline \multirow[b]{2}{*}{ Component } & \multicolumn{2}{|c|}{ Close-up cow TMR } & \multicolumn{2}{|c|}{ Fresh cow TMR } \\
\hline & Farm A & Farm B & Farm A & Farm B \\
\hline $\mathrm{CP}$ & $13.8 \pm 3.0$ & $13.5 \pm 2.0$ & $18.2 \pm 0.7$ & $17.9 \pm 0.8$ \\
\hline $\mathrm{ADF}$ & $31.3 \pm 7.3$ & $28.7 \pm 4.2$ & $18.8 \pm 1.3$ & $19.3 \pm 0.9$ \\
\hline NDF & $48.9 \pm 3.0$ & $47.0 \pm 5.6$ & $31.3 \pm 2.8$ & $31.8 \pm 2.2$ \\
\hline $\mathrm{NE}_{\mathrm{L}}$ (Mcal $\left./ \mathrm{kg}\right)$ & $1.55 \pm 0.06$ & $1.56 \pm 0.04$ & $1.68 \pm 0.03$ & $1.67 \pm 0.02$ \\
\hline $\mathrm{Ca}$ & $1.31 \pm 0.56$ & $1.14 \pm 0.42$ & $0.99 \pm 0.08$ & $0.98 \pm 0.10$ \\
\hline $\mathrm{P}$ & $0.33 \pm 0.07$ & $0.37 \pm 0.03$ & $0.45 \pm 0.01$ & $0.38 \pm 0.02$ \\
\hline $\mathrm{Mg}$ & $0.38 \pm 0.09$ & $0.37 \pm 0.09$ & $0.37 \pm 0.01$ & $0.36 \pm 0.03$ \\
\hline $\mathrm{K}$ & $1.12 \pm 0.09$ & $1.01 \pm 0.18$ & $1.27 \pm 0.06$ & $1.25 \pm 0.08$ \\
\hline $\mathrm{Na}$ & $0.12 \pm 0.04$ & $0.11 \pm 0.03$ & $0.47 \pm 0.05$ & $0.51 \pm 0.09$ \\
\hline
\end{tabular}


ing a Versamax tunable microplate reader (Molecular Devices, Sunnyvale, CA). A commercial solid-phase RIA kit was used to determine plasma concentrations of cortisol (Coat-A-Count, Diagnostic Products, Los Angeles, CA). Intra- and interassay CV for the cortisol RIA were 1.7 and $2.9 \%$, respectively.

Fecal samples were collected fresh and stored on ice until they could be frozen at $-20^{\circ} \mathrm{C}$ for later processing. Steroids from the fecal samples were extracted using the wet extraction method described by Palme (2005). Briefly, $0.5 \mathrm{~g}$ of each raw fecal sample was weighed and vortexed with $5 \mathrm{~mL}$ of $80 \%$ methanol for $30 \mathrm{~min}$. Samples were then centrifuged for $15 \mathrm{~min}$ at $2,800 \times$ $g$ and the supernatant was divided into aliquots and stored at $-20^{\circ} \mathrm{C}$ until further analysis. The DM percentage of each fecal sample was obtained by weighing samples before and after drying in a hot oven $\left(105^{\circ} \mathrm{C}\right)$ for $24 \mathrm{~h}$. Concentrations of fecal cortisol metabolites (11,17-dioxoandrostanes) were measured using a competitive enzyme immunoassay developed by Palme and Möstl (1997) and validated for use in cattle (Palme et al., 1999). Intra- and interassay CV for the fecal cortisol metabolite assay were 3.9 and $6.5 \%$, respectively. To reduce the variation associated with differences in manure consistency, the concentration of fecal cortisol metabolites obtained from the enzyme immunoassay were adjusted for the DM content of the raw fecal sample and reported on a DM basis.

At the end of the study, blood and fecal samples were sorted by week relative to the actual calving date. Samples collected during $d-21$ to -15 relative to the actual calving date were used to represent wk -3 , d -14 to -8 (wk -2 ), and d -7 to -2 (wk -1 ). Samples collected during $\mathrm{d}-1$ were not included in the data set because of the increase in circulating cortisol and NEFA concentrations that occurs during the day before parturition (Vazquez-Añon et al., 1994; Patel et al., 1996).

\section{Determination of Health Outcomes}

For the description of postpartum health status, only disease cases that were recorded by both farms and that used similar case definitions were included. Cases of RP, displaced abomasum (DA), and death (not including voluntary culls) were collected from DairyComp 305 (Valley Agricultural Systems, Tulare, CA) up to 30 DIM. Case definitions for the disease outcomes were discussed with farm staff before the commencement of the study to ensure consistency of diagnosis between farms. Retained placenta was defined as failure to expel the placenta within $24 \mathrm{~h}$ after parturition. Displaced abomasum was diagnosed based on an auscultation of a "ping" during percus- sion of the left side of the abdomen and was generally confirmed during subsequent surgical correction. Cows were classified as subclinically ketotic (SCK) if plasma BHBA concentration from a postpartum blood sample collected between 3 and 10 DIM was $>0.96 \mathrm{mmol} / \mathrm{L}$ (10 $\mathrm{mg} / \mathrm{dL}$; Ospina et al., 2010a). Plasma concentrations of BHBA were measured by enzymatic analysis (BHBA dehydrogenase, kit no. 310, Sigma Chemical, St. Louis, $\mathrm{MO})$. Intra- and interassay CV for the BHBA assay were 2.2 and $5.1 \%$, respectively. Cases of metritis and mastitis were not consistently recorded in the 2 herds and therefore could not be reliably measured. Researchers have shown that plasma Hp concentrations can be used as a diagnostic tool or predictive measure for cows at risk for metritis and mastitis has also been associated with elevated Hp concentrations in milk. Dubuc et al. (2010) reported that odds of metritis were 4 times greater when cows had $\mathrm{Hp}>0.8 \mathrm{~g} / \mathrm{L}$ between $\mathrm{d} 1$ and 7 postpartum (sensitivity: $51 \%$ and specificity: $79 \%$ ), and Huzzey et al. (2009) found that cows with Hp >1 $\mathrm{g} / \mathrm{L}$ on d 3 were 6.7 times more likely to develop severe or mild metritis (sensitivity: $50 \%$ and specificity: 87\%). Wenz et al. (2010) reported Hp concentrations in the milk of severely infected mammary quarters was doubled that of quarters with only mild infection $(0.50$ vs. $1.01 \mathrm{~g} / \mathrm{L}$, respectively). Based on this literature, a postpartum plasma Hp concentration $>1$ g/L (HiHp) was considered a disease outcome in this study. This cutpoint was associated with the higher specificity for the detection of metritis and this was preferred so that a positive result from the test would be associated with a higher probability of the presence of disease, thereby minimizing false positives.

Cows were divided retrospectively into 3 health categories for statistical analyses: (1) "no disorder of interest" (NDI) included cows that did not have RP, DA, SCK, or HiHp or die by $30 \mathrm{DIM}$; (2) "one disorder" included cows that developed only one health disorder (RP, DA, SCK, or HiHp) by 30 DIM; and (3) "more than one disorder or death" included cows that developed 2 or more health disorders (RP, DA, SCK, or $\mathrm{HiHp}$ ) or that died by 30 DIM.

\section{Statistical Analysis}

The associations between categorical variables, parity, and farm and the individual disease outcomes were analyzed using $2 \times 2$ contingency tables generated by the PROC FREQ statement in SAS (version 9.2; SAS Institute, 2009). From these tables, the MantelHaenszel chi-square test statistic was used to determine the type 1 error risk of the relationship. Correlations between NEFA, Hp, plasma cortisol, and fecal cortisol metabolites at each period before calving were deter- 
mined using PROC CORR; for these analyses, data for cows in each health category were pooled into one data set.

Statistical analyses were performed using SAS with cow as the experimental unit. Concentrations of NEFA, $\mathrm{Hp}$, and fecal cortisol metabolites were analyzed as continuous outcomes using PROC MIXED. The differences in these analytes between NDI cows versus cows with one disorder, and between NDI cows versus cows with more than one disorder or death, were analyzed by period (wk $-3,-2$, and -1 ) using the contrast statement. These data were stratified by period rather than analyzed using a repeated measures model due to independent a priori hypotheses by time. Each period was considered an independent test because the concentrations of the analytes of interest will change relative to time from calving and we predicted that the level of association with the health outcome was likely to be influenced by the time lapse between the analyte being tested and the onset of the disease. The model included the fixed effects of farm (A vs. B), parity (PP vs. MP), and health category (NDI, one disorder, more than one disorder or death) and the relevant interaction terms (farm $\times$ health, parity $\times$ health). When an interaction term with $P<0.05$ was detected, data were stratified by that factor.

After completing the plasma cortisol assay, we found that a large number of the samples (53\%) fell below the lowest standard used in the assay $(13.8 \mathrm{nmol} / \mathrm{L})$. Consequently, plasma cortisol was analyzed as a categorical explanatory variable with logistic regression. Plasma cortisol concentrations marking the 95th, 90th, and 75th percentiles (data from PP and MP cows combined) were used as the potential predictive cutpoints for the 2 postpartum health outcomes of interest.

When an association or a tendency for an association was detected $(P \leq 0.1)$ between an analyte and a health outcome using PROC MIXED, the data were evaluated further using multivariable logistic regression analysis. The LOGISTIC procedure in SAS was used to determine if the relationship between the analyte and the health outcome persisted once additional explanatory variables (covariates) were also accounted for. In addition to the analyte of interest (NEFA, Hp, plasma cortisol, or fecal cortisol metabolites), the following explanatory variables (all of which preceded the diagnosis of disease) were considered for each model: farm (A vs. $\mathrm{B})$, parity (PP vs. MP), calving ease (assisted vs. not assisted), twins (yes vs. no), calves born DOA (yes vs. no), and prepartum BCS. Manual backward-stepwise logistic regression was used to remove explanatory variables from the model when $P>0.05$. Odds ratios $(\mathbf{O R})$ were used to describe the level of association between the analyte of interest and the postpartum health out- come (NDI vs. one disorder or NDI vs. more than one disorder or death). The OR is the odds of the disease in the exposed group divided by the odds of disease in the nonexposed group.

\section{RESULTS}

\section{Descriptive Data}

On farm A, the median (range) BCS during the prepartum period was 3.5 (2.25 to 4.75 ) and during the postpartum period was 3.5 (2.0 to 4.5 ). On farm B, median (range) prepartum BCS was 3.5 (1.75 to 4.25) and postpartum was 3.25 (1.75 to 4.0). The lactational incidences of death, DA, and HiHp were not different between the 2 herds $(P>0.20)$; however, farm A had more cases of SCK $(P<0.01)$ and tended to have more cases of $\operatorname{RP}(P=0.06$; Table 2$)$. Farm A had more sets of twins (19 vs. $6 ; P<0.01$ ), but farms did not differ in calves born DOA (12 vs. 14 for farms A and $\mathrm{B}$, respectively). Multiparous cows had more cases of $\mathrm{RP}$ and DA $(P<0.001$ and $P=0.04$, respectively), more twins (24 vs. $1 ; P<0.001$ ), and tended to have fewer calves born DOA (10 vs. $16 ; P=0.07$ ) than PP cows. Primiparous cows tended to have more cases of HiHp $(P=0.08)$. The mean (median) DIM of death for affected cows was 11.7 (12) and for DA was 12.6 (10). The number and proportion of cows that were allocated to the 3 experimentally defined health categories are provided in Table 2 , stratified by parity and farm. Table 3 describes the distribution of health disorders and calving events by the 3 experimentally defined health categories.

During each period before calving, NEFA and fecal cortisol metabolites were positively correlated with each other $(\mathrm{r}=0.19,0.19$, and 0.29 for $\mathrm{wk}-3,-2$, and -1 ; $P<0.001)$, as were NEFA and $\mathrm{Hp}(\mathrm{r}=0.22,0.19$, and 0.41 for wk $-3,-2$, and $-1 ; P<0.001)$. Nonesterified fatty acids was correlated with plasma cortisol during wk -2 and $-1(\mathrm{r}=0.17$ and 0.16 , respectively; $P \leq$ 0.002). Haptoglobin and fecal cortisol metabolites were positively correlated during all periods $(\mathrm{r}=0.13,0.29$, and 0.30 for wk $-3,-2$, and $-1 ; P \leq 0.01$ ), whereas Hp and plasma cortisol were only correlated during wk -2 and -1 ( $\mathrm{r}=0.17$ and $0.16 ; P \leq 0.003)$. At no period before calving did we find a correlation between plasma cortisol and fecal cortisol metabolites $(P>0.48)$.

\section{Analytes by Postpartum Health Status}

$\boldsymbol{N E F A}$. Because of significant parity $\times$ health status interactions in each period before calving $(P \leq 0.02)$, NEFA data were stratified by parity. Multiparous cows with more than one disorder or that died by 30 DIM had 
Table 2. Number of health disorders during the first 30 DIM by farm $(A, n=202 ; B, n=210)$ and parity [primiparous $(\mathrm{PP}), \mathrm{n}=182 ;$ multiparous $(\mathrm{MP}), \mathrm{n}=230$ ], including overall lactational incidence $(\mathrm{n}=412)$

\begin{tabular}{|c|c|c|c|c|c|c|}
\hline \multirow{2}{*}{$\begin{array}{l}\text { Disorder and } \\
\text { health category }{ }^{1}\end{array}$} & \multicolumn{2}{|c|}{ Farm } & \multicolumn{2}{|c|}{ Parity } & \multicolumn{2}{|c|}{ Overall } \\
\hline & $\mathrm{A}$ & $\mathrm{B}$ & $\mathrm{PP}$ & MP & No. & $\%$ \\
\hline Retained placenta (RP) & 28 & 17 & 9 & 36 & 45 & 10.9 \\
\hline Displaced abomasum (DA) & 11 & 14 & 6 & 19 & 25 & 6.1 \\
\hline Subclinical ketosis $(\mathrm{SCK})^{2}$ & 74 & 50 & 46 & 78 & 124 & 30.1 \\
\hline Haptoglobin $>1 \mathrm{~g} / \mathrm{L}(\mathrm{HiHp})^{2}$ & 66 & 80 & 73 & 73 & 146 & 35.4 \\
\hline Died & 7 & 13 & 5 & 15 & 20 & 6.3 \\
\hline NDI & 89 & 94 & 86 & 97 & 183 & 44.4 \\
\hline One disorder & 65 & 62 & 58 & 69 & 127 & 30.8 \\
\hline$>$ One disorder or death & 48 & 54 & 38 & 64 & 102 & 24.8 \\
\hline
\end{tabular}

${ }^{1} \mathrm{NDI}=$ no disorder of interest: cows that did not develop RP, DA, SCK, HiHp or die by 30 DIM; One disorder $=$ cows that developed only one disorder (RP, DA, SCK, or HiHp) by 30 DIM; > One disorder or death = cows that developed 2 or more disorders (RP, DA, SCK, HiHp) or died by $30 \mathrm{DIM}$.

${ }^{2}$ Measured postpartum (3 to 10 DIM).

greater NEFA concentrations than NDI cows during each week before calving, whereas MP cows with only one disorder after calving had greater NEFA relative to the NDI group during wk -1 only. Primiparous cows with more than one disorder or that died by 30 DIM had greater NEFA during wk -2 and -1 relative to $\mathrm{PP}$ NDI cows. Prepartum NEFA concentrations were not different between PP cows with only one postpartum disorder by 30 DIM and those in the NDI category (Table 4).

$\boldsymbol{H p}$. Haptoglobin concentration was greater in $\mathrm{PP}$ cows during wk $-1(0.33$ vs. $0.23 \mathrm{~g} / \mathrm{L} ; P=0.03)$ and tended to be greater during wk $-2(0.34$ vs. $0.26 \mathrm{~g} / \mathrm{L})$ and wk $-3(0.27$ vs. $0.21 \mathrm{~g} / \mathrm{L})$, relative to that in MP cows $(P \leq 0.09)$. Relative to cows in the NDI category, Hp tended to be greater during wk -2 and wk -1 for cows that developed more than one disorder or that died by $30 \mathrm{DIM}(P=0.12$ and 0.09 , respectively; Table
4). No other differences in prepartum Hp were detected between health categories.

Fecal Cortisol Metabolites. In all periods before calving, PP cows had greater fecal cortisol metabolite concentrations than MP cows (wk -3, 1,912 vs. 1,441 $\mathrm{ng} / \mathrm{g}$ of fecal DM; wk $-2,2,035$ vs. $1,560 \mathrm{ng} / \mathrm{g}$ of fecal DM; and wk $-1,2,332$ vs. $1,714 \mathrm{ng} / \mathrm{g}$ of fecal DM; $P$ $<0.001)$. Relative to cows in the NDI category, fecal cortisol metabolite concentrations tended to be greater during wk -3 and wk -2 for cows that developed more than one disorder or that died by 30 DIM $(P=0.07$ and 0.10 , respectively; Table 4$)$. No other differences in prepartum fecal cortisol metabolite concentrations were detected between health categories.

Plasma Cortisol. The concentrations of plasma cortisol that marked the 95th, 90th, and 75th percentiles for all animals were $48.6,36.4$, and $22.0 \mathrm{nmol} / \mathrm{L}$, respectively, during wk $-3 ; 44.5,34.1$, and $22.2 \mathrm{nmol} / \mathrm{L}$,

Table 3. Frequency (no.) of health disorders and calving events and median (range) prepartum BCS in the 3 experimentally defined health categories

\begin{tabular}{|c|c|c|c|c|}
\hline $\begin{array}{l}\text { Disorder and } \\
\text { calving event }{ }^{1}\end{array}$ & $\begin{array}{l}\text { Total no. } \\
\text { of events }\end{array}$ & $\begin{array}{c}\text { NDI } \\
(\mathrm{n}=183)\end{array}$ & $\begin{array}{l}\text { One disorder } \\
(\mathrm{n}=127)\end{array}$ & $\begin{array}{c}>\text { One disorder } \\
\text { or death }(\mathrm{n}=102)\end{array}$ \\
\hline Retained placenta (RP) & 45 & 0 & 10 & 35 \\
\hline Displaced abomasum (DA) & 25 & 0 & 3 & 22 \\
\hline Subclinical ketosis $(\mathrm{SCK})^{2^{2}}$ & 124 & 0 & 48 & 76 \\
\hline Haptoglobin $>1 \mathrm{~g} / \mathrm{L}(\mathrm{HiHp})^{2}$ & 146 & 0 & 66 & 80 \\
\hline Died & 20 & 0 & 0 & 20 \\
\hline Twins & 25 & 1 & 6 & 18 \\
\hline Dead on arrival & 26 & 5 & 8 & 13 \\
\hline Assisted calvings & 106 & 32 & 35 & 36 \\
\hline Prepartum BCS & - & $3.5(2.0-4.25)$ & $3.5(2.5-4.75)$ & $3.5(1.75-4.50)$ \\
\hline
\end{tabular}

${ }^{1} \mathrm{NDI}=$ no disorder of interest: cows that did not develop RP, DA, SCK, HiHp or die by 30 DIM; One disorder = cows that developed only one disorder (RP, DA, SCK, or HiHp) by 30 DIM; > One disorder or death = cows that developed 2 or more disorders (RP, DA, SCK, HiHp) or died by 30 DIM.

${ }^{2}$ Measured postpartum (3 to 10 DIM). 
Table 4. Least squares means $( \pm \mathrm{SE})$ for plasma NEFA, plasma haptoglobin $(\mathrm{Hp})$, and fecal cortisol metabolite (FCORT) concentrations for cows in 3 postpartum health categories ${ }^{1}$ during 3 wk before calving

\begin{tabular}{|c|c|c|c|c|}
\hline \multirow[b]{2}{*}{ Analyte } & \multirow[b]{2}{*}{$\mathrm{n}$} & \multicolumn{3}{|c|}{ Period } \\
\hline & & wk -3 & wk -2 & wk -1 \\
\hline \multicolumn{5}{|c|}{ NEFA (mmol/L), primiparous ${ }^{2}$} \\
\hline NDI & 86 & $0.29 \pm 0.02$ & $0.34 \pm 0.02$ & $0.38 \pm 0.02$ \\
\hline One disorder & 58 & $0.31 \pm 0.02$ & $0.37 \pm 0.02$ & $0.41 \pm 0.03$ \\
\hline \multirow{2}{*}{\multicolumn{5}{|c|}{ NEFA (mmol/L), multiparous ${ }^{2}$}} \\
\hline & & & & \\
\hline NDI & 97 & $0.17 \pm 0.02$ & $0.22 \pm 0.02$ & $0.29 \pm 0.03$ \\
\hline One disorder & 69 & $0.20 \pm 0.02$ & $0.28 \pm 0.03 \dagger$ & $0.40 \pm 0.04^{*}$ \\
\hline$>$ One disorder or death & 64 & $0.29 \pm 0.02^{* * *}$ & $0.42 \pm 0.03^{* * *}$ & $0.60 \pm 0.04^{* * *}$ \\
\hline \multicolumn{5}{|l|}{ Hp (g/L) } \\
\hline NDI & 183 & $0.24 \pm 0.03$ & $0.27 \pm 0.03$ & $0.23 \pm 0.03$ \\
\hline One disorder & 127 & $0.29 \pm 0.03$ & $0.29 \pm 0.04$ & $0.28 \pm 0.04$ \\
\hline$>$ One disorder or death & 102 & $0.18 \pm 0.04$ & $0.34 \pm 0.04 \dagger$ & $0.33 \pm 0.05 \dagger$ \\
\hline \multicolumn{5}{|l|}{ FCORT (ng/g of fecal DM) } \\
\hline NDI & 183 & $1,593.8 \pm 58.4$ & $1,764.5 \pm 66.7$ & $1,979.0 \pm 98.7$ \\
\hline One disorder & 127 & $1,659.4 \pm 69.9$ & $1,678.9 \pm 79.9$ & $1,972.1 \pm 119.5$ \\
\hline$>$ One disorder or death & 102 & $1,777.0 \pm 84.1 \dagger$ & $1,950.9 \pm 92.5 \dagger$ & $2,117.9 \pm 139.4$ \\
\hline
\end{tabular}

${ }^{1} \mathrm{NDI}=$ no disorder of interest: cows that did not develop RP, DA, SCK, HiHp or die by 30 DIM; One disorder = cows that developed only one disorder (RP, DA, SCK, or HiHp) by $30 \mathrm{DIM}$; > One disorder or death = cows that developed 2 or more disorders (RP, DA, SCK, HiHp) or died by 30 DIM.

${ }^{2} \mathrm{NEFA}$ data were stratified by parity due to a significant parity $\times$ health status interaction during each week before calving $(P \leq 0.02)$.

$\dagger P \leq 0.1 ;{ }^{*} P \leq 0.05 ;{ }^{* *} P \leq 0.01 ;{ }^{* * *} P \leq 0.001$ : type I error risk for the differences in these analytes between NDI cows and cows with one disorder, and between NDI cows and cows with more than one disorder or that died.

respectively, during wk -2 ; and $42.5,36.1$, and 24.6 $\mathrm{nmol} / \mathrm{L}$, respectively, during wk -1 . The relationships between these cutpoints and postpartum health status are described in the following section.

\section{Multivariable Logistic Regression Analyses}

Calving ease (assisted versus nonassisted) was the only additional covariate, other than parity, that was associated with the 2 health outcomes of interest in this study $(P \leq 0.007)$. For statistical validity reasons, twinning and DOA calvings could not be included as covariates in these analyses because of the low frequency of these events occurring in the NDI category (Table 3 ).

Prepartum NEFA was the only analyte associated with the development of one disorder by 30 DIM after accounting for parity and calving difficulty; however, this association was detected during wk -1 only. Among MP cows, for every $0.15 \mathrm{mmol} / \mathrm{L}$ increase in plasma NEFA concentration during any $3 \mathrm{wk}$ period before calving, the odds of developing more than one disorder or death by 30 DIM were approximately 2 times greater than the odds of this health outcome without the increase in NEFA; however, among PP cows, plasma NEFA was not associated with postpartum health status although calving assistance was (Table 5).

Prepartum Hp was no longer associated with the development of more than one disorder or death by
30 DIM for either PP or MP cows after accounting for calving assistance as a covariate $(P>0.15)$.

During wk -2 only, the associations of plasma cortisol and fecal cortisol metabolites with postpartum health status (development of more than one disorder or death versus NDI) remained after accounting for calving assistance (Table 6). For every $500 \mathrm{ng} / \mathrm{g}$ of fecal DM increase in fecal cortisol metabolites among MP cows during wk -2 only, the odds of developing more than one health disorder or death increased 1.4 times. During wk -2 , MP cows with plasma cortisol concentrations $>34.1 \mathrm{nmol} / \mathrm{L}$ (90th percentile) tended to have greater odds $(\mathrm{OR}=2.5)$ of developing more than one disorder or dying by 30 DIM, whereas PP cows with plasma cortisol concentrations $>22.2 \mathrm{nmol} / \mathrm{L}$ (75th percentile) tended to have lower odds $(\mathrm{OR}=0.4)$ of developing this health outcome after calving.

\section{DISCUSSION}

The results of this study support the conclusions of others (Kaneene et al., 1997; LeBlanc et al., 2005; Ospina et al., 2010a) that increased concentrations of NEFA, measured during the prepartum period, can be used to identify animals at increased risk for postpartum health disorders. In the present study, however, this relationship depended on the degree of illness after calving (one disorder vs. more than one disorder 
Table 5. Final logistic regression models describing the association between plasma NEFA at 3 periods before calving (accounting for additional covariates) and the risk for the experimental health outcomes of interest: (1) more than one disorder or death by 30 DIM versus NDI, and (2) one disorder by 30 DIM versus $\mathrm{NDI}^{1}$

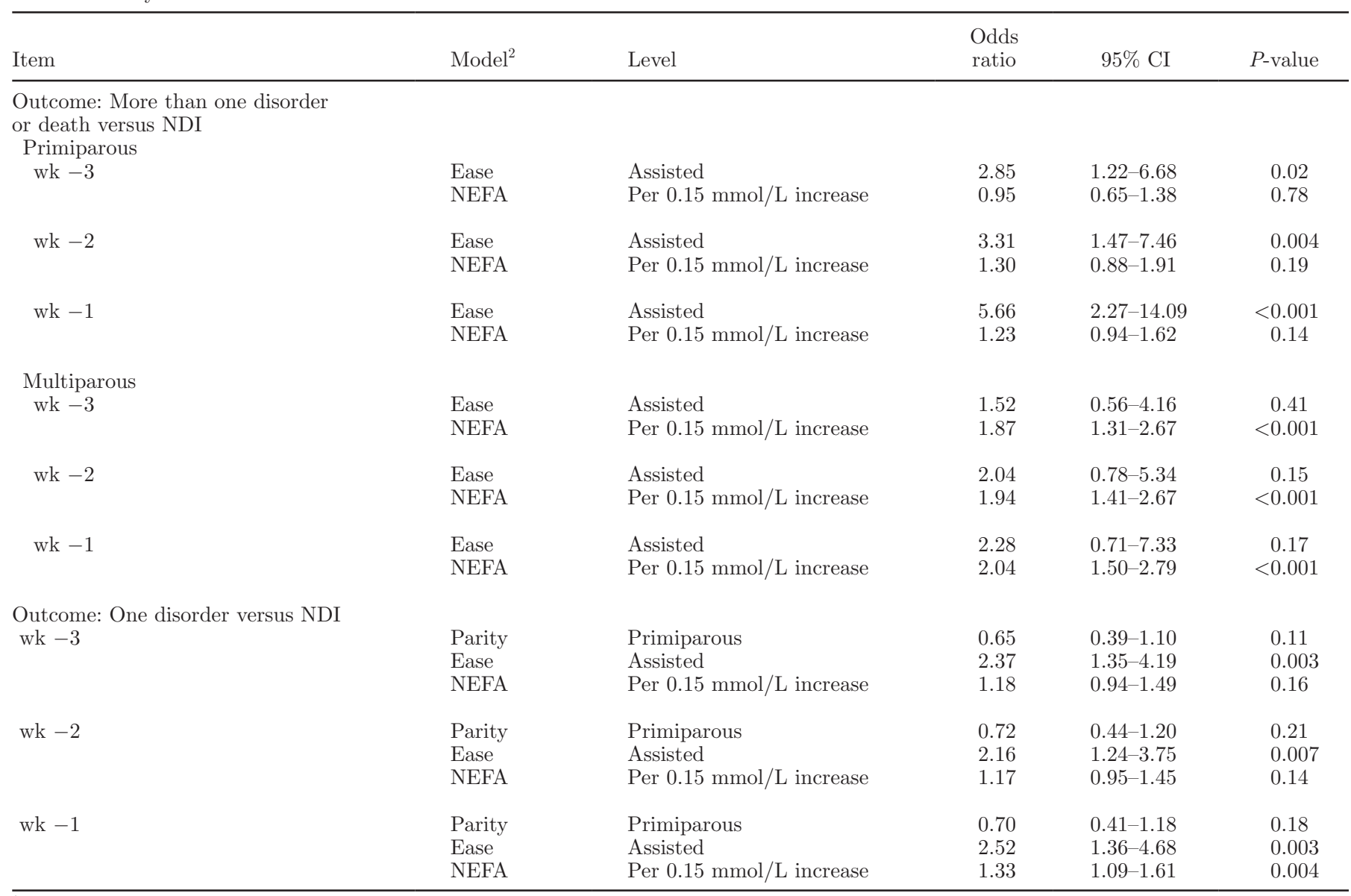

${ }^{1} \mathrm{NDI}=$ no disorder of interest: cows that did not develop RP, DA, SCK, HiHp or die by 30 DIM; one disorder = cows that developed only one disorder (RP, DA, SCK, or HiHp) by 30 DIM; more than one disorder or death = cows that developed 2 or more disorders (RP, DA, SCK, HiHp) or died by 30 DIM.

${ }^{2}$ Analyses were stratified by parity due to a significant NEFA $\times$ parity interaction during wk -3 and $-1(P \leq 0.007)$ and a tendency for an interaction during wk $-2(P=0.11)$.

or death) and parity. A stronger association between prepartum NEFA and the development of multiple disorders (RP, DA, SCK, or HiHp) after calving may suggest that negative energy balance plays a greater role in the pathogenesis of these disorders when they occur together. Including cows that died in this health category did not drive the strength of this relationship. The stronger association between elevated prepartum NEFA and multiple postpartum disorders compared with elevated NEFA and the development of only one disorder after calving remained even after removing cows that had died within 30 DIM.

The relationship between prepartum NEFA and postpartum health status appeared to be greater among MP cows than among PP cows of different health categories. Ospina et al. (2010a) did not observe an interaction between prepartum NEFA and parity in the prediction of cows at risk for DA, clinical ketosis, RP, metritis, or a combination of these disorders after calving. In that study, a larger sample size was used than in the present study, which may have allowed for more sensitivity in identifying differences within PP cows. Other evidence in the literature, however, suggests that PP and MP cows may require different prepartum predictors for postpartum performance. Ospina et al. (2010b) found that PP cows with NEFA concentrations $\geq 0.57$ $\mathrm{mEq} / \mathrm{L}$ during 3 to 14 DIM had greater projected milk yields, whereas MP cows with NEFA concentrations $\geq 0.72 \mathrm{mEq} / \mathrm{L}$ during this period had lower projected milk yields. First-calf heifers may undergo different homeorhetic adaptations to accommodate their first lactation and still support growth and maintenance requirements; this may explain the observed discrepancies between risk factors. Understanding the interac- 
Table 6. Final logistic regression models describing the association between fecal cortisol metabolite concentration (FCORT) and plasma cortisol (P. Cortisol) during wk -2 relative to calving (accounting for additional covariates) and the risk for more than one disorder or death by 30 DIM versus NDI ${ }^{1}$

\begin{tabular}{|c|c|c|c|c|c|}
\hline Item & Model $^{2}$ & Level $^{3}$ & $\begin{array}{l}\text { Odds } \\
\text { ratio }\end{array}$ & $95 \%$ CI & $P$-value \\
\hline $\begin{array}{l}\text { Primiparous } \\
\text { wk }-2\end{array}$ & $\begin{array}{l}\text { Ease } \\
\text { FCORT }\end{array}$ & $\begin{array}{l}\text { Assisted } \\
\text { Per } 500 \mathrm{ng} / \mathrm{g} \text { of fecal DM increase }\end{array}$ & $\begin{array}{l}3.64 \\
0.90\end{array}$ & $\begin{array}{l}1.56-8.50 \\
0.74-1.10\end{array}$ & $\begin{array}{l}0.003 \\
0.31\end{array}$ \\
\hline wk -2 & $\begin{array}{l}\text { Ease } \\
\text { P. Cortisol }\end{array}$ & $\begin{array}{l}\text { Assisted } \\
>22.2 \mathrm{nmol} / \mathrm{L}\end{array}$ & $\begin{array}{l}2.89 \\
0.41\end{array}$ & $\begin{array}{l}1.28-6.56 \\
0.17-0.98\end{array}$ & $\begin{array}{l}0.01 \\
0.05\end{array}$ \\
\hline $\begin{array}{l}\text { Multiparous } \\
\text { wk }-2\end{array}$ & $\begin{array}{l}\text { Ease } \\
\text { FCORT }\end{array}$ & $\begin{array}{l}\text { Assisted } \\
\text { Per } 500 \mathrm{ng} / \mathrm{g} \text { of fecal DM increase }\end{array}$ & $\begin{array}{l}2.79 \\
1.41\end{array}$ & $\begin{array}{l}1.12-6.95 \\
1.12-1.79\end{array}$ & $\begin{array}{l}0.03 \\
0.004\end{array}$ \\
\hline wk -2 & $\begin{array}{l}\text { Ease } \\
\text { P. Cortisol }\end{array}$ & $\begin{array}{l}\text { Assisted } \\
>34.1 \mathrm{nmol} / \mathrm{L}\end{array}$ & $\begin{array}{l}2.66 \\
2.53\end{array}$ & $\begin{array}{l}1.10-6.44 \\
0.87-7.37\end{array}$ & $\begin{array}{l}0.03 \\
0.09\end{array}$ \\
\hline
\end{tabular}

${ }^{1} \mathrm{NDI}=$ no disorder of interest: cows that did not develop RP, DA, SCK, HiHp or die by 30 DIM; more than one disorder or death $=$ cows that developed 2 or more disorders (RP, DA, SCK, HiHp) or died by 30 DIM.

${ }^{2}$ Analyses were stratified by parity during wk -2 due to a FCORT $\times$ parity interaction $(P=0.004)$ and a plasma cortisol $\times$ parity interaction $(P \leq 0.05)$.

${ }^{3}$ Plasma cortisol was modeled as a dichotomized predictor variable based on the 75 th $(22.2 \mathrm{nmol} / \mathrm{L})$ or the 90 th $(34.1 \mathrm{nmol} / \mathrm{L})$ percentile of cortisol concentrations measured among all 412 experimental cows.

tions between parity and known risk factors for disease or production problems will be important for future herd health monitoring programs. Failure to do so may lead to inaccurate assessments of risk and inappropriate managerial actions such as failing to identify the high risk animals and thus neglecting desirable management interventions or incorrectly identifying high risk animals and implementing unnecessary interventions.

Although prepartum NEFA concentrations were positively correlated with plasma haptoglobin, plasma cortisol, and fecal cortisol metabolite concentrations, the correlation coefficients were low and therefore the biological significance of these relationships should not be over-interpreted. Cortisol helps to facilitate NEFA mobilization from adipose tissue during periods of stress to increase energy availability (Sapolsky et al., 2000); however, the biological functions of glucocorticoids are complex. For example, the actions of glucocorticoids are not always lipolytic; excess glucocorticoids are associated with fat accretion in truncal or abdominal areas (Rebuffé-Scrive et al., 1992), and glucocorticoids can stimulate appetite (Santana et al., 1995). Other researchers have described a strong correlation between NEFA and Hp ( $r=0.93$; Kovác et al., 2009) but these correlations incorporated data from the weeks following calving. Excessive negative energy balance, leading to fatty liver syndrome, may damage liver cells thus leading to increased Hp concentrations (Katoh, 2002). In the current study, the correlation between NEFA and $\mathrm{Hp}$ was considered during the prepartum period only, when negative energy balance is typically less of a concern. Cortisol can also stimulate hepatic Hp pro- duction directly (Higuchi et al., 1994). Clearly, NEFA, cortisol, and $\mathrm{Hp}$ are interrelated but these relationships are complex and vary depending on the physiological status of the cow; this may explain why low correlation coefficients were observed in the current study, whereas other researchers report strong correlations between these analytes.

Prepartum Hp concentration was not found to be a significant risk factor for the development of more than one disorder or death by 30 DIM when modeled along with calving assistance. Calving assistance is typically required during a prolonged or particularly difficult calving resulting from a very large or malpositioned calf (Mee, 2008). Dystocia has been identified as a risk factor for retained placenta and metritis (Laven and Peters, 1996; Bruun et al., 2002; Dubuc et al., 2010), disorders that are also associated with elevated Hp concentrations during the week following calving (Huzzey et al., 2009; Dubuc et al., 2010). Among the cows that developed more than one disorder or that died by 30 DIM, $78 \%$ of them had high Hp concentrations (>1g/L) between $\mathrm{d} 3$ and 10 postpartum, and $34 \%$ had RP. Therefore, it is not surprising that calving assistance was strongly associated with this health category and overwhelmed the tendency for an association between prepartum Hp concentration and this health outcome. These results also suggest that a subclinical infection or inflammatory condition during the prepartum period was probably not a major factor contributing to the development of the postpartum disorders measured in this study. Prepartum Hp concentrations do not seem to provide any additional information related to a cow's 
level of risk for postpartum health complications that calving assistance or dystocia could not already provide.

Greater variability in the plasma cortisol data likely explained the weaker association between wk -2 concentrations of this analyte with postpartum health status relative to fecal cortisol metabolites during wk -2 ; the chance of committing a type I error when using wk -2 fecal cortisol concentrations to predict disease in MP cows was much lower $(P=0.004$ vs. $P=0.09)$. Greater daily production of cortisol during the prepartum period, as reflected by greater fecal cortisol metabolite concentrations, could affect the health of transition cows by altering immune function. For example, glucocorticoids can inhibit the synthesis, release, and efficacy of cytokines such as IL-1 and tumor necrosis factor- $\alpha$, important mediators of immune and inflammatory reactions, including the acute phase response, and can alter the migration and function of peripheral cells of the immune system, including lymphocytes, macrophages, and monocytes (reviewed in Sapolsky et al., 2000).

Although no association was found between prepartum fecal cortisol metabolite concentration and postpartum health in PP cows, PP cows with greater plasma cortisol concentrations (75th percentile) during wk -2 relative to calving had a reduced risk of developing more than one disorder or dying by 30 DIM. These seemingly contradictory results could be explained by an exaggerated stress response during sampling in PP cows that are less familiar with handling and the process of sample collection than MP cows. Previous work has shown that the average plasma cortisol concentration increases by about $20 \mathrm{ng} / \mathrm{mL}$ within $10 \mathrm{~min}$ of a heifer being introduced to a novel environment (Veissier and LeNeindre, 1988). It is possible that by the time heifers were sorted and restrained in headlocks many would have had elevated plasma cortisol concentrations before the collection of the blood sample.

The confounding effects of the sample collection procedure also likely explain the lack of correlation between plasma cortisol and fecal cortisol metabolites during the prepartum period. Fecal cortisol metabolite concentrations reflect the amounts of excreted, and thus produced, cortisol 10 to $12 \mathrm{~h}$ before sample collection (Palme et al., 1999). In the current study, this period would have reflected the overnight hours (approximately 0000 to $0300 \mathrm{~h}$ ) and thus, little to no human interaction with the cattle would have occurred. Researchers who validated the use of fecal cortisol metabolites as a measure of cortisol production by demonstrating the parallel concentrations of plasma cortisol and its fecal metabolites following ACTH administration and by reporting the correlation $(\mathrm{r}=0.77 ; P=0.006)$ be- tween ACTH dose and the percentage increase in fecal cortisol metabolites minimized the sampling effect by collecting blood through jugular catheters of animals well-accustomed to handling (Palme et al., 1999).

The natural increase in maternal cortisol production during the days just before parturition (Patel et al., 1996) may have prevented the detection of a relationship between prepartum cortisol and postpartum health during wk -1 . Further, the antibodies used in the fecal cortisol metabolite assay have some cross-reactivity with gonadal steroids of placental origin; this can cause elevated levels of immunoreactive products in the feces of cattle, particularly during the period just before parturition (Möstl et al., 2002). Although data from d -1 were eliminated from the analyses to limit these confounding effects, the results could suggest that samples collected at any time during the week before calving may be influenced by maternal or placental changes in steroid production that are associated with the onset of parturition.

Although an association was found between wk -2 fecal cortisol metabolite concentrations and postpartum health status among multiparous cows, this analyte is probably not a suitable measure for identifying cows at increased risk for postpartum health complications compared with prepartum NEFA. A major challenge for prepartum blood testing programs is the inability to know exactly when parturition will occur; actual calving dates can vary from the predicted dates by \pm 5 d. It would be very difficult for producers to accurately select cows for sampling that were exactly in their second-to-last week prepartum, and thus very difficult for producers to accurately interpret the results of the fecal cortisol metabolite assay without knowing precisely when the sample was collected before parturition. Because prepartum NEFA is associated with health status during each of the $3 \mathrm{wk}$ before calving in MP cows, interpretation of the data would still be possible without knowing the exact proximity to parturition.

\section{CONCLUSIONS}

In general, the relationships between prepartum analytes and postpartum health status were stronger among MP cows than among PP cows, and, with the exception of prepartum NEFA, no associations were detected between prepartum concentrations of our analytes of interest and the occurrence of one disorder (RP, DA, SCK, or HiHP) by 30 DIM. After accounting for important covariates, including parity and calving assistance, prepartum $\mathrm{Hp}$ was not a significant predictor of cows that would go on to develop more than one disorder or die by 30 DIM, and prepartum plasma cortisol and fecal cortisol metabolites were only associated 
with this health category when measured during wk -2 relative to calving. Prepartum NEFA concentrations were associated with the development of more than one disorder or death by 30 DIM during all 3 wk before calving, and the strength of these associations was greater than the strength of the associations between plasma cortisol or fecal cortisol metabolites during wk -2 and this health outcome (lower type I error risk). Using a sampling protocol that mimics field-level herd testing (i.e., cross-sectional sampling with an appropriate sample size), NEFA is a more suitable analyte to evaluate, relative to fecal cortisol metabolites, plasma $\mathrm{Hp}$, or plasma cortisol for identifying opportunities to improve herd health.

\section{ACKNOWLEDGMENTS}

The authors sincerely thank the owners and staff of the New York State commercial dairies for their participation in this study. We also thank the following staff and students at Cornell University in Ithaca, New York: Katie Schoenberg and Laurie Winkelman for their insights during the planning stages of this project; Charlene Ryan, Tom Linden, Jen Lukas, and Mark Cummings for their invaluable assistance with data collection and sample processing; and Ramona Ehrhardt for her assistance during the laboratory analyses. Funding for this study was provided by the New York Farm Viability Institute (Syracuse, NY).

\section{REFERENCES}

Arthington, J. D., S. D. Eichert, W. E. Kunkle, and F. G. Martin 2003. Effect of transportation and commingling on the acute-phase protein response, growth, and feed intake of newly weaned beef calves. J. Anim. Sci. 81:1120-1125.

Bruun, J., A. K. Ersbøll, and L. Alban. 2002. Risk factors for metritis in Danish dairy cows. Prev. Vet. Med. 54:179-190.

Cook, C. J., D. J. Mellor, P. J. Harris, J. R. Ingram, and L. R. Matthews. 2000. Hands-on and hands-off measurement of stress. Pages 123-146 in The Biology of Animal Stress. G. P. Moberg and J. A. Mench, ed. CABI Publishing. Wallingford, UK.

Dubuc, J., T. F. Duffield, K. E. Leslie, J. S. Walton, and S. J. LeBlanc. 2010. Risk factors for postpartum uterine diseases in dairy cows. J. Dairy Sci. 93:5764-5771.

Eckersall, P. D. 2000. Recent advances and future prospects for the use of acute phase proteins as markers of disease in animals. Rev. Med. Vet. (Toulouse) 151:577-584.

Friend, T. H., F. C. Gwazdauskas, and C. E. Polan. 1979. Change in adrenal response from free stall competition. J. Dairy Sci. 62:768-771.

Friend, T. H., C. E. Polan, F. C. Gwazdauskas, and C. W. Heald. 1977. Adrenal glucocorticoid response to exogenous adrenocorticotropin mediated by density and social disruption in lactating cows. J. Dairy Sci. 60:1958-1963.

Grant, R. J., and J. L. Albright. 1995. Feeding behavior and management factors during the transition period in dairy cattle. J. Anim. Sci. 73:2791-2803

Gupta, S., B. Earley, S. T. Ting, and M. A. Crowe. 2005. Effect of repeated regrouping and relocation on the physiological, immuno- logical, and hematological variables and performance of steers. J. Anim. Sci. 83:1948-1958.

Higuchi, H., N. Katoh, T. Miyamoto, E. Uchida, A. Yuasa, and K. Takahashi. 1994. Dexamethasone-induced haptoglobin release by calf liver parenchymal cells. Am. J. Vet. Res. 55:1080-1085.

Hirvonen, J., G. Huszenicza, M. Kulcsàr, and S. Pyörälä. 1999. Acutephase response in dairy cows with acute postpartum metritis. Theriogenology 51:1071-1083.

Huzzey, J. M., T. F. Duffield, S. J. LeBlanc, D. M. Veira, D. M. Weary, and M. A. G. von Keyserlingk. 2009. Short communication: Haptoglobin as an early indicator of metritis. J. Dairy Sci. 92:621-625.

Kaneene, J. B., R. Miller, T. H. Herdt, and J. C. Gardiner. 1997. The association of serum nonesterified fatty acids and cholesterol, management and feeding practices with peripartum disease in dairy cows. Prev. Vet. Med. 31:59-72.

Katoh, N. 2002. Relevance of apolipoproteins in the development of fatty liver and fatty liver-related peripartum diseases in dairy cows. J. Vet. Med. Sci. 64:293-307.

Kovác, G., C. Tóthová, O. Nagy, H. Seidel, and J. Konvicná. 2009. Acute phase proteins and their relation to energy metabolites in dairy cows during the pre- and postpartal period. Acta Vet. (Brno) 78:441-447.

Laven, R. A., and A. R. Peters. 1996. Bovine retained placenta: Aetiology, pathogenesis and economic loss. Vet. Rec. 139:465-471.

Lay, D. C., T. H. Friend, R. D. Randel, O. C. Jenkins, D. A. Neuendorff, G. M. Kapp, and D. M. Bushong. 1996. Adrenocorticotropic hormone dose response and some physiological effects of transportation on pregnant Brahman cattle. J. Anim. Sci. 74:1806-1811.

LeBlanc, S. J., K. E. Leslie, and T. F. Duffield. 2005. Metabolic predictors of displaced abomasum in dairy cattle. J. Dairy Sci. 88:159-170.

Lomborg, S. R., L. R. Nielsen, P. M. Heegaard, and S. Jacobsen. 2008. Acute phase proteins in cattle after exposure to complex stress. Vet. Res. Commun. 32:575-582.

Mee, J. F. 2008. Prevalence and risk factors for dystocia in dairy cattle: A review. Vet. J. 176:93-101.

Mormède, P., S. Andanson, B. Aupérin, B. Beerda, D. Guémené, J. Malmkvist, X. Manteca, G. Manteuffel, P. Prunet, C. G. van Reenen, S. Richard, and I. Veissier. 2007. Exploration of the hypothalamic-pituitary-adrenal function as a tool to evaluate animal welfare. Physiol. Behav. 92:317-339.

Möstl, E., J. L. Maggs, G. Schrötter, U. Besenfelder, and R. Palme. 2002. Measurement of cortisol metabolites in faeces of ruminants. Vet. Res. Commun. 26:127-139.

Nennich, T. D., J. H. Harrison, L. M. VanWieringen, D. Meyer, A. J. Heinrichs, W. P. Weiss, N. R. St-Pierre, R. L. Kincaid, D. L. Davidson, and E. Block. 2005. Prediction of manure and nutrient excretion from dairy cattle. J. Dairy Sci. 88:3721-3733.

Oetzel, G. R. 2004. Monitoring and testing dairy herds for metabolic disease. Vet. Clin. North Am. Food Anim. Pract. 20:651-674.

Ospina, P. A., D. V. Nydam, T. Stokol, and T. R. Overton. 2010a. Evaluation of nonesterified fatty acids and beta-hydroxybutyrate in transition dairy cattle in the northeastern United States: Critical thresholds for prediction of clinical diseases. J. Dairy Sci. 93:546-554.

Ospina, P. A., D. V. Nydam, T. Stokol, and T. R. Overton. 2010b. Associations of elevated nonesterified fatty acids and beta-hydroxybutyrate concentrations with early lactation reproductive performance and milk production in transition dairy cattle in the northeastern United States. J. Dairy Sci. 93:1596-1603.

Palme, R. 2005. Measuring fecal steroids. Guidelines for practical application. Ann. N. Y. Acad. Sci. 1046:75-80.

Palme, R., and E. Möstl. 1997. Measurement of cortisol metabolites in faeces of sheep as a parameter of cortisol concentration in blood. Int. J. Mammary Biol. 62(Suppl. II):192-197.

Palme, R., C. Robia, W. Baumgartner, and E. Möstl. 2000. Transport stress in cattle as reflected by an increase in faecal cortisol metabolite concentrations. Vet. Rec. 146:108-109.

Palme, R., C. Robia, S. Messmann, J. Hofer, and E. Möstl. 1999. Measurement of faecal cortisol metabolites in ruminants: A non- 
invasive parameter of adrenocortical function. Wiener Tierärztliche Monatschrift 86:237-241.

Patel, O. V., T. Takahashi, N. Takenouchi, M. Hirako, N. Sasaki, and I. Domeki. 1996. Peripheral cortisol levels throughout gestation in the cow: Effect of stage of gestation and foetal number. Br. Vet. J. $152: 425-432$.

Peter, A. T., and W. T. Bosu. 1987. Peripartal endocrine changes associated with retained placenta in dairy cows. Theriogenology 28:383-394.

Rabiee, A. R., K. L. Macmillan, and F. Schwarzenberger. 2001. The effect of level of feed intake on progesterone clearance rate by measuring faecal progesterone metabolites in grazing dairy cows. Anim. Reprod. Sci. 67:205-214.

Rebuffé-Scrive, M., U. A. Walsh, B. McEwen, and J. Rodin. 1992. Effect of chronic stress and exogenous glucocorticoids on regional fat distribution and metabolism. Physiol. Behav. 52:583-590.

Santana, P., S. F. Akana, E. S. Hanson, A. M. Strack, R. J. Sebastian, and M. F. Dallman. 1995. Aldosterone and dexamethasone both simulate energy acquisition whereas on the glucocorticoid alters energy storage. Endocrinology 136:2214-2222.

Sapolsky, R. M., L. M. Romero, and A. U. Munck. 2000. How do glucocorticoids influence stress responses? Integrating permissive, suppressive, stimulatory, and preparative actions. Endocr. Rev. $21: 55-89$.

SAS Institute. 2009. SAS and STAT User's Guide. Release 9.2. SAS Institute Inc., Cary, NC.
Sheldon, I. M., D. E. Noakes, A. Rycroft, and H. Dobson. 2001. Acute phase protein responses to uterine bacterial contamination in cattle after calving. Vet. Rec. 148:172-175.

Skinner, J. G., R. A. Brown, and L. Roberts. 1991. Bovine haptoglobin response in clinically defined field conditions. Vet. Rec. 128:147-149.

Thun, R., E. Eggenberger, K. Zerobin, T. Lüscher, and W. Vetter. 1981. Twenty-four-hour secretory pattern of cortisol in the bull: Evidence of episodic secretion and circadian rhythm. Endocrinology 109:2208-2212.

Vazquez-Añon, M., S. Bertics, M. Luck, R. R. Grummer, and J. Pinheiro. 1994. Peripartum liver triglyceride and plasma metabolites in dairy cows. J. Dairy Sci. 77:1521-1528.

Veissier, I., and P. LeNeindre. 1988. Cortisol responses to physical and pharmacological stimuli in heifers. Reprod. Nutr. Dev. 28:553562.

Wenz, J. R., L. K. Fox, F. J. Muller, M. Rinaldi, R. Zeng, and D. D. Bannerman. 2010. Factors associated with concentrations of select cytokine and acute phase proteins in dairy cows with naturally occurring clinical mastitis. J. Dairy Sci. 93:2458-2470.

Wildman, E. E., G. M. Jones, P. E. Wagner, R. L. Boman, H. F. Trout, and T. N. Lesch. 1982. A dairy cow body condition scoring system and its relationship to selected production variables in high producing Holstein dairy cattle. J. Dairy Sci. 65:495-501. 